\title{
The Regional Differences in Mortality Attributable to Alcohol in the Czech Republic in 2017
}

\author{
GAVUROVÁ, B. ${ }^{1}$,TARHANIČOVÁ, M. ${ }^{2}$, KULHÁNEK, A. ${ }^{3}$
}

1 | Tomas Bata University, Faculty of Management and Economics, Centre for Applied Economic Research, Zlín, Czech Republic

2 | Technical University of Košice, Faculty of Mining, Ecology, Process Control and Geotechnologies, Košice, Slovakia

3 | Charles University, First Faculty of Medicine and General University Hospital in Prague, Department of Addictology, Prague, Czech Republic
Citation | Gavurová, B., Tarhaničová, M., \& Kulhánek, A. (2021). The regional differences in mortality attributable to alcohol in the Czech Republic in 2017. Adiktologie, 21(1), 43-50. https://doi.org/10.35198/01-2021-001-0004
INTRODUCTION: Public authorities daily deal with the negative consequences of drinking alcohol. Alcohol consumption results in morbidity and mortality, that economically presents lost productivity. Mortality and morbidity related to alcohol differs in regions and in populations. AlMS: This study aims to find out which regions of the Czech Republic are similar in mortality attributable to alcohol. There are many diagnoses specified by the International Classification of Diseases, that relate to alcohol wholly or partially, therefore this study estimates which diagnoses mostly relate to alcoholic death. As there are differences in alcohol attributable fractions, this study provides an insight into the examined issues separately for males and females. METHODS: The mortality attributable to alcohol was calculated based on attributable fractions. To identify similar regions in mortality attributable to alcohol, the cluster analysis was conducted. SAMPLE: The sample consisted of 111443 deaths (out of which $50.65 \%$ deaths attributable to men, $49.35 \%$ deaths attributable to women) that occurred in the Czech Republic in 2017. RESULTS: Five clusters were identified as optimal in regard to alcohol mortality not only for men but also for women. The analysis shows differences in mortality related to alcohol between men and women. Diseases of liver and malignant neoplasms of digestive organs were mostly related to alcohol mortality in 2017. CONCLUSIONS: Based on the results it might be conclude that differences in mortality related to alcohol does not reflect the differences in economic development of the Czech regions.

\section{Keywords | Czech Republic - Attributable Fractions - Alcohol - Regional Cluster Analysis - Avoidable Mortality}

Grant affiliation | This work was supported by the GCDPC, Grant No. A-86-19, and by the institutional support programme Progres No. 006/LF1: “Economic quantification of the social cost of alcohol, tobacco, and illicit drug abuse in the case of the Czech Republic". This research was funded by the R0/2020/05 Internal Grant Scheme of the Tomas Bata University in Zlin. 


\section{INTRODUCTION}

While in 1990 global alcohol consumption was at the level of 5.9 l/person, in 2017 it was at the level of 6.5 l/person (WHO, 2018). In low- and middle-income countries, such as India or Vietnam, alcohol consumption is increasing, accompanied by an improved standard of living and economic development. On the contrary, there has been a significant decline in alcohol consumption in countries such as Russia, the UK, and Azerbaijan. It is estimated that the global level of alcohol consumption will reach the level of $7.6 \mathrm{l} /$ person by 2030 . According to the study of Manthey et al. (2019), the reasons for the different levels of alcohol consumption are cultural and religious customs, the implementation of alcohol measures, and economic growth.

According to the Institute of Health Metrics and Evaluation (IHME), drug use is a significant cause of death worldwide. In 2017, the riskiest factor of death was high blood pressure (10.44 mil. deaths), following by smoking, with 7.1 mil. deaths. Alcohol accounted for 2.84 mil. deaths and became the ninth riskiest factor of death. From 1990 to 2017, there was an increase in alcohol consumption globally.

According to OECD (2020), the alcohol consumption level in the Czech Republic between 1994 and 2017 remained in the range from 11 1/person to 12.1 1/person. Within the Visegrád countries, the Czech Republic has had the highest alcohol consumption since 2008. On the other hand, there was a decrease in alcohol consumption in all the Visegrád countries during the economic crisis that started in 2008. Considering the Visegrád Group, the lowest consumption of beer and spirits was reported in the Czech Republic. The prevalence of heavy episodic drinking in the Czech Republic belongs among the highest globally. Mravčík et al. (2019) also indicate a decline in alcohol use among children and adolescents; however, alcohol-related mortality is increasing.

\section{LITERATURE REVIEW}

During the last century, alcohol consumption and its consequences have been the subject of various studies (e.g. Zabransky et al., 2011; Mlčoch et al., 2019, Shield et al., 2013; Webster et al., 2019). These studies aim to quantify the relationship between alcohol use and deaths. In some studies, the authors calculate the attributable fractions on the basis of interviews or meta-analysis. A more commonly used approach is to implement the attributable fractions on the basis of a literature review. The reason for studying attributable fractions is that it helps to quantify the number of deaths and thus their economic consequences across the world.

To evaluate the relationship between alcohol and cancer, Bagnardi et al. (2001) performed a search of the epidemiological literature from 1966 to 2000 using several bibliographic databases. Spear et al. (2018), Wood et al. (2018), and Ronksley et al. (2011) examined the relationship between alcohol and death (El Ansari et al., 2013). Cirrhosis and other diagnoses that are attributable to alcohol are a significant cause of morbidity and mortality globally. The burden and underlying causes differ across locations and demographic groups (Sepanlou et al., 2020). There are also differences between the deaths of women and men (Gavurova et al., 2019).

Moreover, some studies are concerned about the consequences of drinking. There are many consequences, not only economic but also with alcohol as the cause of divorce, crimes committed under its influence, and traffic accidents (e.g. Zabransky et al., 2011; Mravčík et al., 2019; Webster et al., 2019). According to Zabransky et al. (2011), the social cost of alcohol use in the Czech Republic in 2011 was at the level of CZK 16,354.8 mil. (EUR 602.96 mil.), which represents $0.46 \%$ of the GDP of the Czech Republic.

Historically, Slovakia and Czechia formed one country, Czechoslovakia. This fact caused the similarities between both countries that may be found in the demographic characteristics of their citizens. It may be supposed that if variability exists within Slovak regions, there might be variability in the Czech regions too. Gavurova \& Kubak (2017) provide information about mortality connected to diseases of circulatory systems in Slovak regions. They showed the differences when comparing the Slovak regions. In Slovakia, the regions with the highest economic development accounted for a lower share of deaths attributable to ischemic diseases comparing to less developed regions.

To compare the similarities of Slovak regions, Kubak et al. (2019) used cluster analysis. Many authors, e.g. Kvíčalová et al., (2014), Mazurek (2011), and Majerova \& Nevima (2017), have used cluster analysis to make a comparison of the Czech regions in economic terms. In the study of Mazurek (2011), the Czech Republic was divided into five economically similar clusters: 1. the Ústí nad Labem and Moravia-Silesia regions, 2. the capital city, Prague, 3. the Central Bohemia, Pilsen, and Karlovy Vary regions, 4. the Hradec Králové, Pardubice, Vysočina, Olomouc, and Zlín regions, and 5. the South Bohemia, South Moravia, and Liberec regions. On the basis of different types of income, Kvíčalová et al. (2014) divided the Czech Republic into three clusters. In the first cluster, there were the South Bohemia, Zlín, Hradec Králové, Ústí nad Labem, Pardubice, Olomouc, Moravia-Silesia, Vysočina, Central Bohemia, Pilsen, and South Moravia regions. The second cluster contained the Karlovy Vary and Liberec regions. In the last cluster, there was the capital city, Prague.

Even though studies on regional differences regarding the economic situation exist, studies concerned with alcohol-attributable deaths still represent an unexplored area. This study aims to fill this gap. It is at the intersection of problematic alcohol drinking with various consequences and regional differences. It provides an overview of alcohol-related death patterns in regions across the Czech Republic in 2017.

\section{METHODS}

For this study, we used the data from the death register of the Czech Republic provided for the further research of the project Grant No. A-86-19 by the Institute of Health Information and Statistics of the Czech Republic. The register of deaths contains 
information about deaths within the period 1994-2017. The following attributes describe each death in this register: gender, age at death, the primary cause of death (ICD-10), external cause of the death (ICD-10), the region where the deceased lived, marital status, etc. To analyse this data, SPSS Clementine and R-studio were used.

First, we calculated the number of deaths attributable to alcohol. Some diagnoses are wholly attributable to drinking alcohol, but the rest of them only partly so. To decide whether the diagnosis is wholly or partly attributable to alcohol, we used the attributable fractions presented in previous studies (e.g. Zabransky et al., 2011; Ye et al., 2019; Mlčoch et al., 2019, Shield et al., 2013; Patra et al., 2007; Rehm et al., 2007; Webster et al., 2019). As there were differences between men's and women's attributable fractions, we distinguish the AF for both genders separately. According to Webster et al. (2019), the attributable fractions are calculated using the formula [1].

$$
A A F=\frac{\sum_{i=1}^{k} P(i)[R R(i)-1]}{\sum_{i=0}^{k} P(i)[R R(i)-1]+1}
$$

where

$\mathbf{i}$ - exposure to alcohol (in average grams of ethanol consumed per day),

RR(i) - relative risk at a given exposure level,

$\mathbf{P}(\mathbf{i})$ - the proportion of people at a given exposure level.

After the identification of attributable fractions, we multiplied the number of deaths (separately for every identified diagnosis and gender) by the corresponding attributable fraction.

\subsection{The cluster analysis}

For each of the 14 Czech regions and for both genders, we calculated the number of deaths separately. After that, cluster analysis was conducted. To identify similar regions considering the number of deaths linked to every diagnosis connected to drinking alcohol, we used cluster analysis. Cluster analysis is the classification of data objects into similar groups, called clusters (Kaufman \& Rousseeuw, 2009). Cluster analysis is applicable in many situations in scientific and business investigations (Odell \& Duran, 1974). To calculate the distance, we used the function dist().

According to Maechler et al. (2019), the function dist() computes and returns the distance matrix. It is computed by using a specified distance measure to compute the distances between the rows of a data matrix(). Next, we used the function hclust(), which performs a hierarchical cluster analysis using a set of dissimilarities for the $n$ objects being clustered. Initially, each object is assigned to its cluster, and then the algorithm proceeds iteratively, at each stage joining the two most similar clusters, continuing until there is just a single cluster. Distances between clusters are recomputed at each stage by the Lance-Williams dissimilarity update formula according to Ward's minimum variance method.

\section{RESULTS}

\subsection{The comparison of alcohol-attributable mortality}

In 2017, alcohol-related diagnoses were divided into the 23 groups presented in Table 1 (for women) and into the 25 groups presented in Table 2 (for men). These tables are the presentation of the minimum and maximum shares of alcohol-related deaths according to specified diagnoses in all alcohol-related deaths across the Czech regions.

In the case of women (see Table 1), the maximum share of tuberculosis (A15-A19) in alcohol deaths is 0.35\%. That means $0.35 \%$ of all alcohol-attributable deaths were related to tuberculosis. Most alcohol-related deaths in women were connected to diseases of the liver (K70). Out of all alcoholrelated deaths, 23.08-42.98\% were related to diseases of the liver (K70). The diagnoses with the smallest share in alcohol deaths are D00-D36 (Benign neoplasms, except benign neuroendocrine tumours) with 0-0.29\%, A15-A19 (Tuberculosis) with $0-0.35 \%$, and K86.0 (Alcohol-induced chronic pancreatitis) with $0-0.66 \%$.

As shown in both Table 1 and Table 2, there is variability in the share of diagnoses attributable to alcohol. In the case of the diagnosis $\mathrm{C00}-\mathrm{C} 14$, the minimum share of deaths across the Czech regions was $0.76 \%$, and the maximum share was 3.94\%.

As shown in Table 2, the highest share of men's alcoholattributable deaths is related to liver disease. This share is between 26.04 and $45.28 \%$. On the contrary, the diagnoses with the least share of alcohol deaths are D00-D36 (Benign neoplasms, except benign neuroendocrine tumours) with a share of 0-0.22\%, K22.6 (Gastro-oesophageal laceration-haemorrhage syndrome) with a share of 0-0.23\%, L40 (Psoriasis) with a share of $0-0.22 \%$, and G62.1 (Alcoholic Polyneuropathy) with a share of $0-0.32 \%$. The toxic effect of alcohol as the external cause of death is related to 2.55-10.98\% of alcohol-related deaths. Compared to women, there are significant differences in the share of diagnoses related to alcohol.

\subsection{The regional differences in mortality}

In the Czech Republic, there are 14 regions, which are economically different. While the capital city, Prague (CZ010), and the Central Bohemia (CZ020), South Moravia (CZ064), and Moravia-Silesia (CZ080) regions are the ones with the highest share of national GDP and are economically the most developed, the Liberec (CZ051) and Karlovy Vary (CZ041) regions are the ones with the lowest share of Czech GDP.

On the basis of the number of alcohol-attributable deaths divided according to ICD-10, in the case of women, the Czech Republic was divided into clusters as presented in Figure 1:

1. the Hradec Králové (CZ052), Pardubice (CZ053), Vysočina (CZ063), and South Bohemia (CZ031) regions; 
2. the Karlovy Vary (CZ041), Pilsen (CZ032), and Liberec (CZ051) regions;

3. the Moravia-Silesia region (CZ080);

4. the Ústí nad Labem (CZ042), Olomouc (CZ071), and Zlín (CZ072) regions;

5. the capital city, Prague (CZ010), and the Central Bohemia (CZ020) and South Moravia (CZ064) regions.

On the basis of the number of deaths according to ICD-10 attributable to alcohol, in the case of men the Czech Republic was divided into five clusters as presented in Figure 2:

1. the Karlovy Vary (CZ041) and Hradec Králové (CZ052) regions;

2. the Liberec (CZ051), Pardubice (CZ053), Vysočina (CZ063), South Bohemia (CZ031), and Pilsen (CZ032) regions;

3. the capital city, Prague (CZ010) and the Ústí nad Labem (CZ042), Olomouc (CZ071), and Zlín (CZ072) regions;

4. the Moravia-Silesia region (CZ080);

5. the Central Bohemia (CZ020) and South Moravia (CZ064) regions.

\section{DISCUSSION}

As the results show, there are differences between the maximum and minimum share of alcohol-related deaths according to ICD-10, as well as differences within genders across the Czech regions. While in the case of women, the diagnosis T51 (Toxic effect of alcohol) represents only $0-5.85 \%$ of all alcohol-related deaths, in the case of men, this diagnosis represents almost double that value (2.55-10.98\%). Men's alcohol-attributable deaths related to external causes of morbidity and mortality are also higher. The difference might be seen in the number of identified groups of diagnoses (23 for women compared to 25 for men) as well.

The types of diseases that are attributable to drinking alcohol also differ between the genders. This may be the consequence of diagnosis specificity, such as C50 (Malignant neoplasms of the breast), which is typical only for women. However, differences are also seen in diagnoses such as K29.2 (Alcoholic gastritis) and L40 (Psoriasis). Both diagnoses were connected only with the alcohol-attributable deaths of men.

As the results of the cluster analysis revealed, the optimal number of clusters in both cases was five. It allows us to compare the regions in a better manner. Comparing the results of the cluster analysis between genders, we found similarities in the Moravia-Silesia region as this region forms a separate category of regions based on deaths attributable to alcohol. The similarities within genders were also found in Cluster 5 for both genders (the Central Bohemia and South Moravia regions). In Cluster 3 (men) and Cluster 4 (women), a similarity was found, since the clusters contain the same regions (the Ústí nad Labem, Olomouc, and Zlín regions). As the Pardubice, Vysočina, and South Bohemia regions were in the same cluster, we suppose there is also a similarity in terms of deaths attributable to alcohol in those regions.

As we may see, when regions are compared on the basis of alcohol-attributable deaths, there are also differences between genders. Considering the women's cluster analysis, Prague, as an economically highly efficient region, was in the same cluster as the Ústí nad Labem, Olomouc, and Zlín regions. However, its economic strength is completely different. For men, Prague was in the same cluster as the Central Bohemia and South Moravia regions. On the basis of GDP, the economic efficiency of these regions is visible and similar.

In comparison to the results of Mazurek (2011), who analysed the similarity of the Czech regions according to economic indicators, the clusters that were created involved regions differently. While in the first cluster, there were the Ústí nad Labem and Moravia-Silesia regions, the capital city, Prague, was in a separate cluster. It does not conform to the results of our cluster analysis as in the case of both genders Prague was in clusters with completely different regions. Mazurek (2011) also distinguished the other clusters $(3,4,5)$. Cluster 3 was formed of the Central Bohemia, Pilsen, and Karlovy Vary regions. Cluster 4 contained the Hradec Králové, Pardubice, Vysočina, Olomouc, and Zlín regions. The last cluster consisted of the South Bohemia, South Moravia, and Liberec regions.

Kvíčalová et al. (2014) divided the regions of the Czech Republic into three clusters based on income indicators. In their first cluster, there were the South Bohemia, Zlín, Hradec Králové, Ústí nad Labem, Pardubice, Olomouc, Moravia-Silesia, Vysočina, Central Bohemia, Pilsen, and South Moravia regions. The second cluster contained the Karlovy Vary and Liberec regions, which have the lowest share of Czech GDP. In the last cluster, there was the capital city, Prague, as the region with the highest share of Czech GDP, with the highest urbanization rate, and more developed. While economic development is evident in the Prague region, there are great differences in the income of the citizens that give rise to the social problems of individuals and their families.

The results of Kvíčalová and Mazurek differ, even though the cluster analysis of both studies is based on economic indicators. To explain these differences, it is necessary to take into consideration the differences in the methods and approaches used and the fact that when the studies took place differs as well. Moving forward, the differences in cluster analysis presented by this study compared to the studies of Kvičalová and Mazurek may arise from the fact that alcohol-related deaths are connected to criminality. In general, criminality is at its highest in the most and least developed regions (Mravčík et al., 2019). That means that even if a region is well developed, if the level of alcohol-related criminality is high, the alcohol-related deaths will be more numerous.

Considering that alcohol consumption is increasing mainly in low- and middle-income countries and applying this fact to the Czech Republic, the regions with lower economic development are in greater danger of higher alcohol consumption. With a higher consumption of alcohol, the probability of dying an alcohol-related death is increasing. To be able to confirm whether socially more vulnerable groups of the population are more prone to alcohol consumption, it is necessary to conduct more specific and deeper analysis. 
Table 1 | Regional maximum and minimum percentage of deaths attributable to alcohol according to ICD-10, women

\begin{tabular}{|c|c|c|c|c|}
\hline \multirow{2}{*}{$\begin{array}{l}\text { Code of } \\
\text { diagnosis }\end{array}$} & \multirow{2}{*}{$\begin{array}{c}\text { ICD } 10 \\
\text { chapters }\end{array}$} & \multirow{2}{*}{ Diagnosis group name } & \multirow{2}{*}{$\frac{\min }{(\text { in } \%)}$} & \multirow{2}{*}{$\frac{\max }{\text { (in \%) }}$} \\
\hline & & & & \\
\hline A15-A19 & I. & Tuberculosis & 0 & 0.35 \\
\hline $\mathrm{C} 00-\mathrm{C} 14$ & II. & Malignant neoplasms of lip, oral cavity, and pharynx & 0.76 & 3.94 \\
\hline C15-C26 & II. & Malignant neoplasms of digestive organs & 7.56 & 13.44 \\
\hline C30-C39 & II. & Malignant neoplasms of respiratory and intrathoracic organs & 0 & 0.90 \\
\hline C50 & II. & Malignant neoplasms of breast & 6.24 & 12.64 \\
\hline D00-D36 & II. & Benign neoplasms, except benign neuroendocrine tumors & 0 & 0.29 \\
\hline D37-D48 & II. & Neoplasms of uncertain behavior, polycythemia vera, and myelodysplastic syndromes & 0.33 & 1.14 \\
\hline F10 & V. & Mental, Behavioral and Neurodevelopmental disorders & 0 & 4.99 \\
\hline G31.2 & VI. & Degeneration of nervous system due to alcohol & 0 & 1.47 \\
\hline G40-G41 & VI. & Episodic and paroxysmal disorders & 0.47 & 2.78 \\
\hline$|10-| 15$ & IX. & Hypertensive diseases & 4.73 & 12.37 \\
\hline $130-152$ & $\mathrm{IX}$ & Other forms of heart disease & 1.94 & 6.70 \\
\hline $160-169$ & IX. & Cerebrovascular diseases & 2.36 & 6.36 \\
\hline $180-189$ & IX. & Diseases of veins, lymphatic vessels and lymph nodes, not elsewhere classified & 0 & 1.63 \\
\hline J09-J18 & $\mathrm{X}$ & Influenza and pneumonia & 1.76 & 8.26 \\
\hline K22.6 & $\mathrm{XI}$ & Gastro-esophageal laceration-hemorrhage syndrome & - & 0.77 \\
\hline K70 & $\mathrm{XI}$ & Diseases of liver & 23.8 & 42.98 \\
\hline K74 & $\mathrm{XI}$ & Diseases of liver & 2.23 & 9.6 \\
\hline K85.2 & $\mathrm{XVI}$ & Alcohol-induced acute pancreatitis & 0 & 1.47 \\
\hline K86.0 & XIX. & Alcohol-induced chronic pancreatitis & 0 & 0.66 \\
\hline R95-R99 & XVIII. & Symptoms, signs and abnormal clinical and laboratory findings, not elsewhere classified & 2.45 & 8.15 \\
\hline T51 & XIX. & Toxic effect of alcohol & - & 5.85 \\
\hline V01-Y89 & $X X$ & External causes of morbidity and mortality & 1.80 & 8.44 \\
\hline
\end{tabular}

Source: Own compilation

Figure 1 | Clusters of Czech regions with a similar level of deaths attributable to alcohol, women, 2017

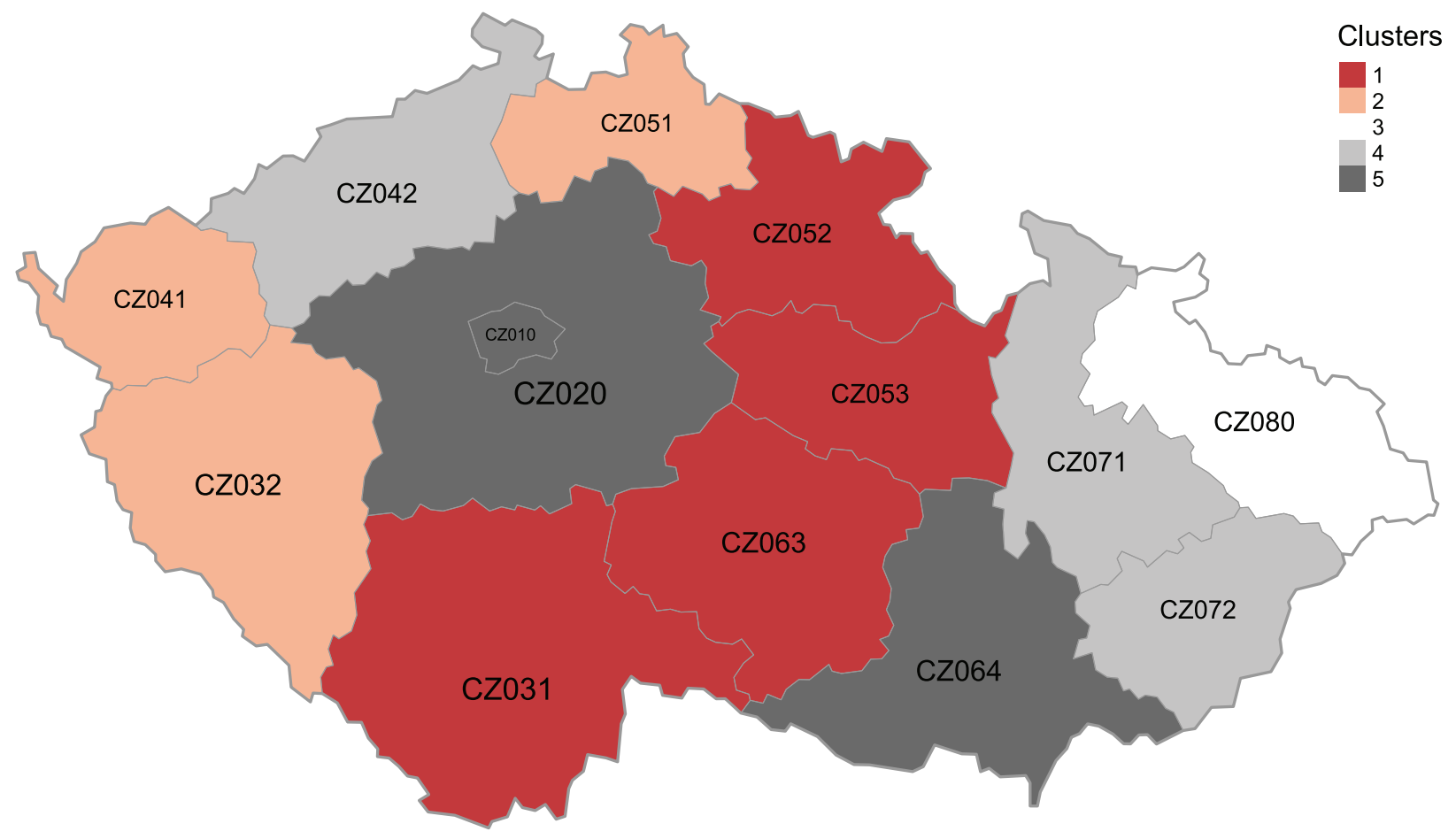


Table 2| Regional maximum and minimum percentage of deaths attributable to alcohol according to ICD-10, men

\begin{tabular}{|c|c|c|c|c|}
\hline \multirow{2}{*}{$\begin{array}{l}\text { Code of } \\
\text { diagnosis }\end{array}$} & \multirow{2}{*}{$\begin{array}{c}\text { ICD } 10 \\
\text { chapters }\end{array}$} & \multirow{2}{*}{ Diagnosis group name } & \multirow{2}{*}{$\frac{\min }{(\text { in } \%)}$} & \multirow{2}{*}{$\frac{\max }{(\text { in } \%)}$} \\
\hline & & & & \\
\hline A15-A19 & I. & Tuberculosis & 0 & 0.36 \\
\hline $\mathrm{C} 00-\mathrm{C} 14$ & II. & Malignant neoplasms of lip, oral cavity and pharynx & 2.71 & 7.71 \\
\hline C15-C26 & II. & Malignant neoplasms of digestive organs & 12.46 & 19.94 \\
\hline C30-С39 & II. & Malignant neoplasms of respiratory and intrathoracic organs & 0.56 & 2.35 \\
\hline D00-D36 & II. & Benign neoplasms, except benign neuroendocrine tumors & 0 & 0.22 \\
\hline D37-D48 & V. & Neoplasms of uncertain behavior, polycythemia vera and myelodysplastic syndromes & 0.85 & 1.91 \\
\hline F10 & VI. & Mental, Behavioral and Neurodevelopmental disorders & 0.61 & 6.26 \\
\hline G31.2 & VI. & Degeneration of nervous system due to alcohol & 0 & 0.36 \\
\hline G40-G41 & VI. & Episodic and paroxysmal disorders & 0 & 2.20 \\
\hline G62.1 & IX. & Alcoholic polyneuropathy & 0 & 0.32 \\
\hline$|10-| 15$ & IX. & Hypertensive diseases & 4.47 & 9.89 \\
\hline $130-152$ & IX. & Other forms of heart disease & 1.76 & 4.83 \\
\hline 160-169 & IX. & Cerebrovascular diseases & 1.60 & 4.87 \\
\hline 180-189 & IX. & Diseases of veins, lymphatic vessels and lymph nodes, not elsewhere classified & 0 & 1.6 \\
\hline J09-J18 & $\mathrm{X}$ & Influenza and pneumonia & 1.96 & 5.53 \\
\hline K22.6 & $\mathrm{XI}$. & Gastro-esophageal laceration-hemorrhage syndrome & 0 & 0.23 \\
\hline K29.2 & $X I$ & Alcoholic gastritis & 0 & 0.31 \\
\hline K70 & XI. & Diseases of liver & 26.4 & 45.28 \\
\hline K74 & $\mathrm{XI}$ & Diseases of liver & 2.25 & 5.85 \\
\hline K85.2 & XI. & Alcohol induced acute pancreatitis & 0 & 2.58 \\
\hline K86.0 & $\mathrm{XI}$ & Alcohol-induced chronic pancreatitis & 0 & 1.6 \\
\hline L40 & XII. & Psoriasis & 0 & 0.22 \\
\hline R95-R99 & XVIII. & Symptoms, signs and abnormal clinical and laboratory findings, not elsewhere classified & 1.20 & 2.88 \\
\hline T51 & XIX. & Toxic effect of alcohol & 2.55 & 10.98 \\
\hline V01-Y89 & $\mathrm{XX}$ & External causes of morbidity and mortality & 4.79 & 14.18 \\
\hline
\end{tabular}

Source: Own compilation

Figure 2 | Clusters of Czech regions with a similar level of deaths attributable to alcohol, men, 2017

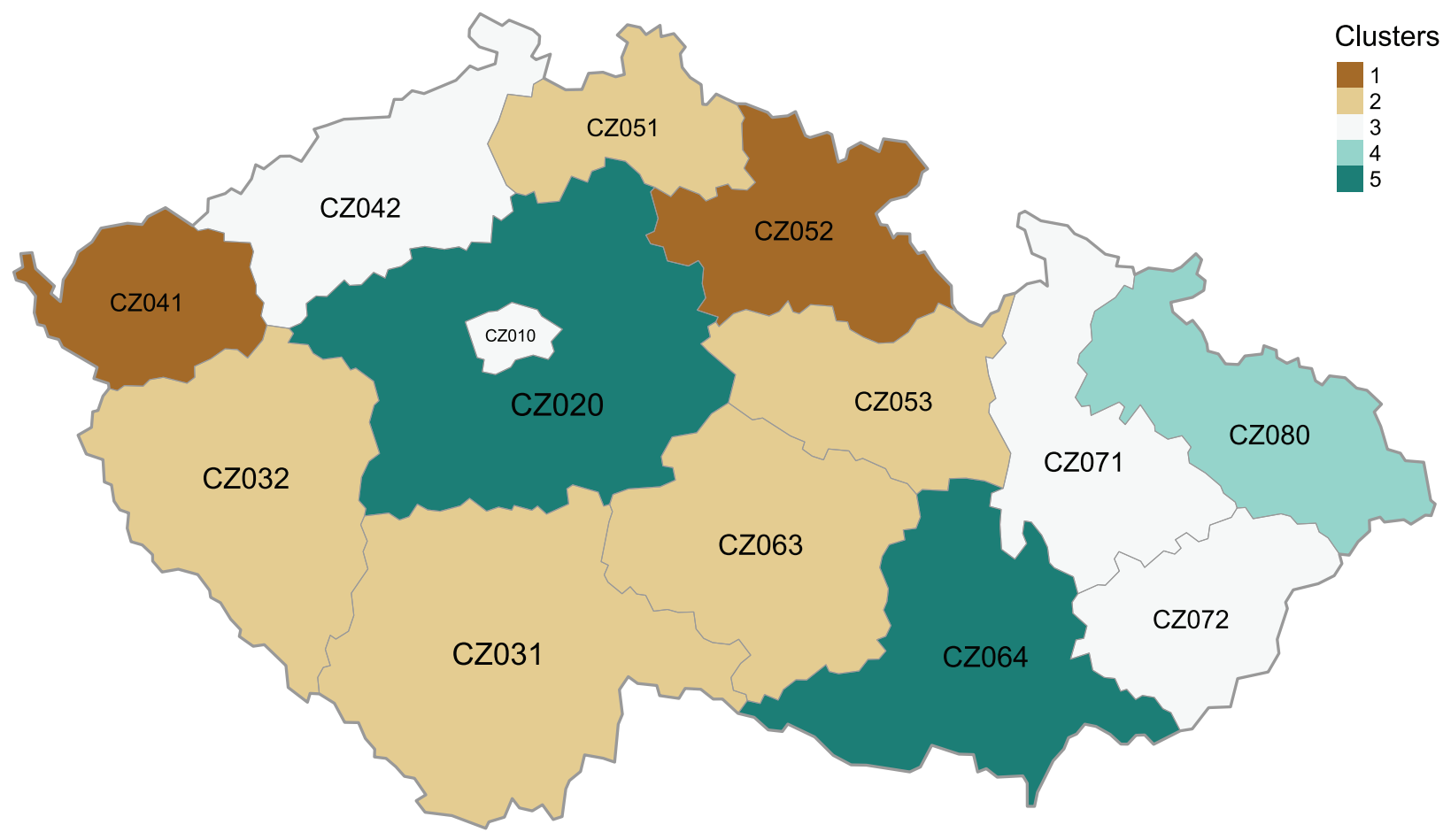




\section{CONCLUSION}

This paper identifies the regional differences caused by alcohol-related mortality in 2017 in the case of the Czech Republic. It allows policymakers to identify the regional disparities better and set the alcohol-related policy more efficiently. Citizens' safety and quality of life occupy an important position in governance processes and a well-established policy allows the negative consequences of drinking alcohol to be reduced. As there are many types of diagnoses related to drinking alcohol that differ between the genders, this study provides an insight into the issues under examination for both sexes.

In conclusion, it is necessary to examine further the relation of alcohol-related mortality to economic indicators (GDP, income, employment rate, etc.) and to social indicators that enable the current situation of the country to be described. The causality between socio-demographic factors needs to be examined over a longer period as well.

Authors' contribution: B.G. and M.T. contributed to the study and proposed the study design. A.K. designed the initial form of the manuscript. M.T. performed the statistical analysis and participated in the data interpretation and preparation of the manuscript. B.G. conducted the literature review and summary of related work. B.G., M.T. and A.K. supervised the statistical analysis and participated in the preparation of the manuscript. All authors contributed to the article and approved the final version of the manuscript.
Declaration of interest: No conflict of interest. 


\section{REFERENCES}

Bagnardi, V., Blangiardo, M., La Vecchia, C., \& Corrao, G. (2001). Alcohol consumption and the risk of cancer: A meta-analysis.

Alcohol Research \& Health, 25(4), 263-270.

https://www.ncbi.nlm.nih.gov/pmc/articles/PMC6705703/

Baliunas, D., Patra, J., Rehm, J., Popova, S., Kaiserman, M., Taylor, B., \& Benjamin Taylor, C. (2002). Smoking-attributable mortality and expected years of life lost in Canada 2002: Conclusions for prevention and policy. Chronic Diseases in Canada, 27(4), 154-162. https://europepmc.org/article/med/17623561

Britton, A., \& McPherson, K. (2001). Mortality in England and Wales attributable to current alcohol consumption. Journal of Epidemiology and Community Health, 55(6), 383-388. https://jech.bmj.com/content/55/6/383.info

Collins, D. J., \& Lapsley, H. M. (1996). The social costs of drug abuse in Australia in 1988 and 1992. Australian Govt. Pub. Service. https://catalogue.nla.gov.au/Record/1094035

El Ansari, W., Sebena, R., \& Stock, C. (2013). Socio-demographic correlates of six indicators of alcohol consumption: Survey findings of students across seven universities in England, Wales and Northern Ireland. Archives of Public Health, 71(1), 29. https://doi.org/10.1186/2049-3258-71-29

Gavurová, B., \& Kubák, M. (2017). Impact of selected socio-demographic factors on the development of mortality due to circulatory system diseases in the Slovak Republic. Central European Journal of Public Health, 25, S94-S103. https://doi.org/10.21101/cejph.a5054

Gavurová, B., Kubák, M., \& Kulhánek, A. (2019). Age-gender mortality study on alcohol-induced deaths in Slovakia. Central European Journal of Public Health, 27, S40-S47. https://doi.org/10.21101/cejph.a5765

Kaufman, L., \& Rousseeuw, P. J. (2009). Finding groups in data: An introduction to cluster analysis. John Wiley \& Sons.

Kubák, M., Gavurová, B., \& Kulhánek, A. (2019). Spatial analysis of alcoholrelated mortality in Slovakia. Central European Journal of Public Health, 27, S48-S54. https://doi.org/10.21101/cejph.a5766

Kvičalová, J., Mazalová, V., \& Široký, J. (2014). Identification of the differences between the regions of the Czech Republic based on the economic characteristics. Procedia Economics and Finance, 12, 343-352. https://doi.org/10.1016/s2212-5671(14)00354-2

Majerova, I., \& Nevima, J. (2017). The measurement of human development using the Ward method of cluster analysis. Journal of International Studies, 10(2), 239-257. https://doi.org/10.14254/2071-8330.2017/10-2/17

Manthey, J., Shield, K. D., Rylett, M., Hasan, O. S. M., Probst, C., \& Rehm, J. (2019). Global alcohol exposure between 1990 and 2017 and forecasts until 2030: A modelling study. The Lancet, 393(10190), 2493-2502. https://doi.org/10.1016/S0140-6736(18)32744-2

Mazurek, J. (2011). Comparison of impacts of the financial crisis on the Czech Republic regions by cluster analysis. In Proceedings of the 13th International conference on finance and banking (pp. 396-404). https://www.researchgate. net/publication/311509521_Comparison_of_Impacts_of_the_Financial_Crisis_ on_the_Czech_Republic_Regions_by_Cluster_Analysis

Mlčoch, T., Chadimová, K., Doležal, T., Dolejší, D., Hájičková, B., Mazalová, M., \& Lamblová, K. (2019). Společenské náklady konzumace alkoholu v České republice. Závěrečná zpráva. Úřad vlády České republiky. http://www.iheta.org/ ext/publication/files/Report_merged_grant_alkohol_2019-04-10 - final.pdf

Mravčík, V., Chomynová, P., Nechanská, B., Černíková, T., \& Csémy, L. (2019). Alcohol use and its consequences in the Czech Republic. Central European Journal of Public Health, 27, S15-S28. https://doi.org/10.21101/cejph.a5728

Odell, D., \& Duran, D. (1974). The cluster problem and preliminary ideas. In Cluster Analysis (pp. 1-31). Springer. https://doi.org/10.1007/978-3-642-46309-9_1

OECD. (2020). Alcohol consumption (indicator).

https://doi.org/10.1787/e6895909-en (accessed on 1 February 2020).

Patra, J., Taylor, B., Rehm, J. T., Baliunas, D., \& Popova, S. (2007). Substanceattributable morbidity and mortality changes to Canada's epidemiological profile:
Measurable differences over a ten-year period. Canadian Journal of Public Health, 98(3), 228-234. https://doi.org/10.1007/BF03403718

Rehm, J., Gnam, W., Popova, S., Baliunas, D., Brochu, S., Fischer, B., Patra, J., Sarnocinska-Hart, A., \& Taylor, B. (2007). The costs of alcohol, illegal drugs, and tobacco in Canada, 2002. Journal of Studies on Alcohol and Drugs, 68(6), 886-895. https://doi.org/10.15288/jsad.2007.68.886

Ronksley, P. E., Brien, S. E., Turner, B. J., Mukamal, K. J., \& Ghali, W. A. (2011). Association of alcohol consumption with selected cardiovascular disease outcomes: A systematic review and meta-analysis. BMJ, 342(7795), 479. https://doi.org/10.1136/bmj.d671

Maechler, M., Rousseeuw, P., Struyf, A., Hubert, M., Hornik, K., Studer, M., Roudier, P., Ganzalez, J., \& Murphy, K. (2019). "Finding groups in data": Cluster analysis extended. https://svn.r-project.org/R-packages/trunk/cluster

Sepanlou, S. G., Safiri, S., Bisignano, C., Ikuta, K. S., Merat, S., Saberifiroozi, M., Poustchi, H., Tsoi, D., Colombara, D. V., Abdoli, A., Adedoyin, R. A., Afarideh, M., Agrawal, S., Ahmad, S., Ahmadian, E., Ahmadpour, E., Akinyemiju, T., Akunna, C. J., Alipour, V., ... Malekzadeh, R. (2020). The global, regional, and national burden of cirrhosis by cause in 195 countries and territories, 1990-2017: A systematic analysis for the Global Burden of Disease Study 2017. The Lancet Gastroenterology and Hepatology, 5(3), 245-266. https://doi.org/10.1016/ S2468-1253(19)30349-8

Shield, K., Parry, C., \& Rehm, J. (2013). Chronic diseases and conditions related to alcohol use. Alcohol Research: Current Reviews, 35(2), 155-173.

Spear, L. P. (2018). Effects of adolescent alcohol consumption on the brain and behaviour. Nature Reviews Neuroscience, 19(4), 197-214. https://doi.org/10.1038/nrn.2018.10

Webster, L., Angus, C., Brennan, A., Gillespie, D., Court, R., \& Street, R. (2019). Smoking attributable fractions for adult diseases in England. University of Sheffield. https://www.sheffield.ac.uk/polopoly_fs/1.828724!//ile/ScHARR_AAFs.pdf

WHO. (2018). Global status report on alcohol and health 2018. World Health Organization. https://apps.who.int/iris/bitstream/hand le/10665/274603/9789241565639-eng.pdf?ua=1

Wood, A. M., Kaptoge, S., Butterworth, A., Nietert, P. J., Warnakula, S., Bolton, T., Paige, E., Paul, D. S., Sweeting, M., Burgess, S., Bell, S., Astle, W., Stevens, D., Koulman, A., Selmer, R. M., Verschuren, M. W. M., Sato, S., Njølstad, I., Woodward, M., . . Danesh, J. (2018). Risk thresholds for alcohol consumption: Combined analysis of individual-participant data for 599912 current drinkers in 83 prospective studies. The Lancet, 391(10129), 1513-1523. https://doi.org/10.1016/S0140-6736(18)30134-X

Ye, Y., Shield, K., Cherpitel, C. J., Manthey, J., Korcha, R., \& Rehm, J. (2019). Estimating alcohol-attributable fractions for injuries based on data from emergency department and observational studies: a comparison of two methods. Addiction, 114(3), 462-470. https://doi.org/10.1111/add.14477

Zabransky, T., Belackova, V., Stefunkova, M., Vopravil, J., \& Langrova, M. (2011). Společenské náklady uživání alkoholu, tabáku a nelegálních drog v Č́R v roce 2007. Centrum adiktologie, Psychiatrická klinika, 1. LF UK v Praze a VFN v Praze. https://www.adiktologie.cz/file/352/01-coi-monografie-web.pdf 